\title{
MAKNA DAN IDEOLOGI PUNK
}

\author{
Daniar Wikan Setyanto \\ Program Studi Desain Komunikasi Visual \\ Fakultas IImu Komputer, Universitas Dian Nuswantoro Semarang \\ daniarwikan@gmail.com
}

\begin{abstract}
Abstrak
Punk Sebagai sebuah subkultur telah diadaptasi oleh para remaja Indonesia bukan hanya sebagai semangat bermusik, namun merambah sebagai ideologi dan gaya hidup. Punk merupakan warisan budaya dari barat yang awalnya bergerak pada bidang musik, namun lambat lain punk telah menjadi sebuah identitas global yang mewakili para remaja radikal yang memiliki visi anti kemapanan dan anti pemerintah. Selain ideologinya yang kontroversi, punk mempengaruhi dinamika fashion di dunia. Asesoris punk diadaptasi oleh budaya bopuler sebagai pernak-pernik fashion. Kini punk, telah menjadi bagian dari dunia fashion di seluruh dunia. Apa sebenarnya yang melatar belakangi munculnya Punk? bagaimana Punk bisa berkembang di Indonesia?
\end{abstract}

Kata Kunci: punk, fashion, budaya populer.

\section{PENDAHULUAN}

Punk secara etimologis berasal dari bahasa Inggris, yaitu "Public United not Kindom", kemudian disingkat menjadi P.U.N.K, atau dalam bahasa indonesia berarti sebuah kesatuan / komunitas di luar kerajaan/pemerintahan. Punk muncul pertama kali di Inggris pada tahun 60-an, pada waktu itu punk hanya sebatas pemberontakan di bidang musik, meskipun akhirnya justru merambah sampai menjadi subkultur. Pada waktu itu musik di Inggris didominasi oleh kaum rocker, yang notabene memiliki skil yang tinggi dalam musikalitas, ritme melodi gitar yang rumit dan cepat, suara tinggi, serta syair cinta yang melankolis. Selain rock, aliran musik lain seperti jazz, pop, klasik juga ikut tenar. Punk kemudian muncul membawa semangat baru para remaja pecinta musik pada waktu itu, yaitu kelompok musisi yang mengapresiasi music rock namun dengan keterbatasan skill dan permodalan. Ciri music punk adalah distorsi gitar yang tajam dengan beat drum yang cepat tak beraturan, musik punk juga dikenal dengan penggunaan acord yang simpel karena hanya terdiri dari 2-3 acord saja. Namun dalam setiap kali aksi panggung punk selalu menonjol karena karakternya yang atraktif, ugalugalan, bahkan brutal. pada setiap konser punk juga dikenal istilah moshing (penonton membentuk lingkaran kemudian saling membantingkan diri satu sama lain). Selain atraktif, punk juga dikenal dengan dandanan mereka yang nyentrik seperti potongan mohawk ala suku Indian (rambut dibuat seperti duri mendongak keatas), kaos bergambar tengkorak, jaket dengan berbagai macam assesoris bordir dan metal, gelak atau kalung besi, tubuh penuh tatto, sepatu boots, piercing, bahkan make up wajah seperti eye shadow dan lipstik hitam. Bagi mereka kostum tersebut merupakan simbol akan semangat punk yang identik dengan anti kemapanan, anarkisme, vandalisme, anti sosial, kriminal kelas rendah, dan kaum terabaikan. 
Ada masa dimana komunitas punk sulit dibedakan dengan kaum skinhead, meski memiliki semangat yang sama yaitu anti kemapanan dan kelas bawah, skinhead sebenarnya berbeda dengan punk. Skinhead merupakan subkultur yang lahir di London, Inggris berbarengan dengan punk, hanya saja skinhead lebih identik dengan potongan botak dan kelas pekerja yang rasis dan neo-Nazi, namun dalam bermusik gaya antara punk dan skinhead hampir sama, saat ini keduanya seakan-akan menyatu dalam ideologi yang sama.

Dalam bermusik para punker (sebutan bagi komunitas punk) mengaburkan batas antara idealisme seni dan kenyataan hidup, sehingga kecenderungan mereka memprovokasi audiens secara terang-terangan, dengan perform kualitas rendah, mereka lebih mengedepankan aksi panggung yang penuh dengan kehebohan dan brutalitas. Hal tersebut karena adanya keyakinan bahwa penampilan fisik dan aksi panggung mereka adalah sebuah poin lebih dari komunitas punk. Lirik-lirik lagu punk selalu meneriakkan protes terhadap kejamnya dunia, kritik terhadap penguasa, rasa frustasi dan anti romantisme, hal tersebut karena dipicu oleh ketidak sukaan meraka terhadap para artis pada masa itu seperti Rolling Stones, Beatles, Elvis yang cenderung mengangkat tema-tema cinta yang sahdu dan menyayat hati.

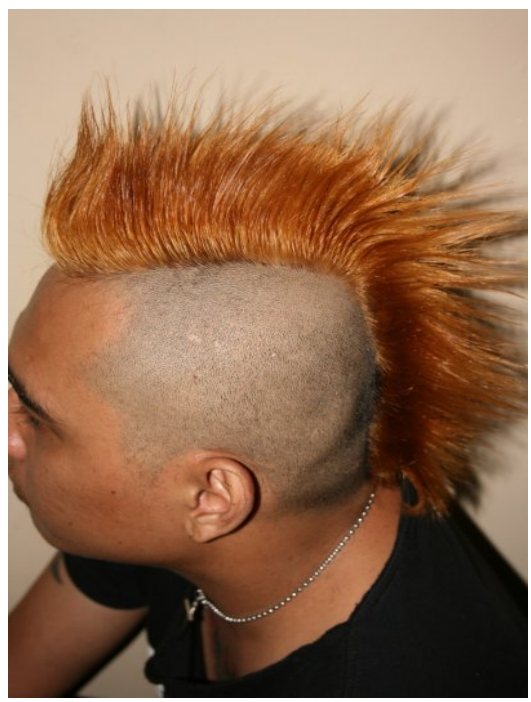

Gambar 1. Model rambut mohawk ciri dari komunitas punk

Meski berawal dari musik, punk sedikit demi sedikit berubah menjadi sebuah gaya hidup yang penuh dengan pandangan dan ideologi, hal tersbut dikarenakan adanya pengertian bahwa hebohnya penampilan (apperance/form) harus disertai dengan hebohnya pemikiran (idea/content). Musik-musik mereka penuh dengan pandangan sosial politik yang akhirnya terpatri dalam kehidupan mereka sehari-hari. Apalagi komunitas punk merupakan komunitas tertindas dari kalangan bawah, pada tahun 1970an pemerintah Inggris menetapkan pajak yang tinggi sehingga di negara tersebut marak dengan kemiskinan, kelaparan, kriminalitas dan kesenjangan sosial. Para punker akhirnya mulai merambah jalanan, mereka berjuang disisi yang selain musik yaitu dengan mendemo penguasa ataupun vandalisme yang ujungnya adalah sebuah kritik buat penguasa kerajaan Inggris. Karena komunitas punk semakin banyak dan mereka 
mulai merambah jalanan, maka lahirlah street punk (punk jalanan) atau komunitas punk yang menggelandang/hidup dijalanan. Street punk semakin meninggalkan semangat awal bermusik namun justru semakin mengarah ke gaya hidup yang berorientasi pada fashion dan kenakalan remaja.

Pada tahun 1990an, saat media elektronik menjadi sangat maju keberadaan komunitas punk mulai tercium media dan disoroti secara tajam diseluruh dunia, tentu saja hal tersebut membuat punk semakin popoler sehingga menjadi sebuah subkultur yang mendunia. Pada masa itu juga punk mulai masuk ke wilayah asia termasuk indonesia, diawali di Bandung yang notabene adalah kota fashion, banyak remaja mulai berdandan ala punk dan turun kejalan-jalan untuk mengamen. Punk semakin banyak dari tahun ketahun karena adanya band-band punk yang sukses seperti Rancid dari California dan Sex Pistols dari Inggris. Keberadaan mereka yang mengglobal membuat punk menjadi trend diseluruh dunia, bahkan muncul pengimitasian gaya punk yang akhirnya melahirkan fashion punk, yaitu mengadaptasi gaya kostum punk tanpa menganut ideologinya.
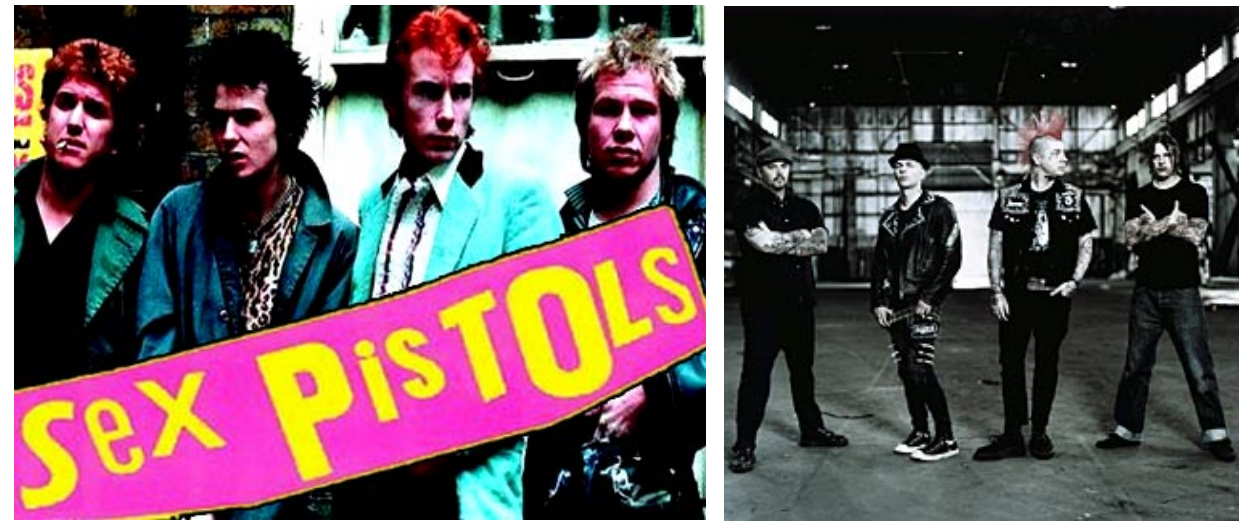

Gambar 2 dan 3. (kiri) Band Sex Pistols dan (kanan) Band Rancid

\section{METODE PENELITIAN}

Penelitian dilakukan dengan menggunakan metode pengumpulan data secara deskriptif kualitatif. Data didapat dengan menggunakan metode observasi dan studi pustaka. Data yang akan digunakan dalam penelitian ini ada dua macam, yaitu:

a. Data primer: pada penelitian ini data primer yang digunakan adalah semua data yang didapat secara langsung dengan mengobservasi kehidupan, fashion, dan tokoh Punk yang biasa dijumpai di pinggir jalan besar, khususnya di kota besar seperti Jogjakarta dan Semarang.

b. Data sekunder: dalam penelitian ini diambil dari studi pustaka terkait punk yang paling cocok untuk analisa ini.

Data yang telah didapat nantinya akan disimpan, diolah dan dianalis menggunakan semiotika. Metode ini digunakan untuk merumuskan makna-makna yang ada di setiap item ikonik kehidupan punk dengan membaca tanda-tanda identitas punk seperti bentukfashion. 


\section{HASIL DAN PEMBAHASAN}

\subsection{MEMBACA MAKNA FASHION PUNK}

Keberadaan band-band punk seperti Sex Pistols dan Rancid membuat demam fashion punk semakin banyak, gaya punk bahkan diadaptasi oleh band-band beraliran lain seperti heavy metal, rock dan trash. Pengimitasian gaya punk tentunya juga merambah Indonesia, karena banyak para remaja di sini yang mengidolakan band-band punk. Pengimitasian terjadi karena sifat remaja yang labil sehingga selalu mengadaptasi halhal yang mereka sukai, meski sebenarnya mereka (kaum remaja) bukan seorang musisi, namun semangat dan gaya fashion punk sangat mempengaruhi kehidupan mereka.

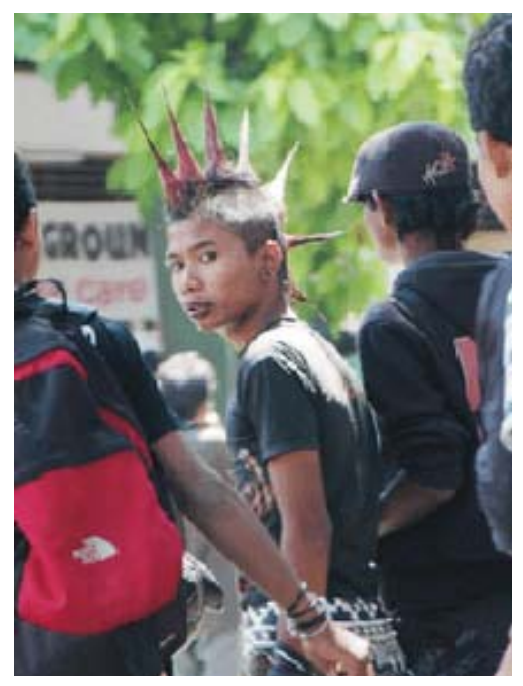

Gambar 4. Foto anak punk Jogja

Apakah fashion punk mempunyai arti? Jawabannya adalah iya. Semiotika mempercayai segala hal yang ada di dunia ini mempunyai makna, tak terkecuali adalah fashion punk. Aart van Zoest dalam bukunya "Semiotik" (1978) mengatakan bahwa simbol dalam musik sangat jelas keberadaannya. Pengenalan jenis, sejarah dan gaya tergantung pada unsur-unsur simbolis dalam tanda kompleks, yakni karya musik. Dengan demikian, penggunaan asesoris fashion pada pemusik termasuk dalam simbolitas musik karena berhubungan erat dengan gaya hidup dan sejarahnya. Berikut adalah analisis makna setiap item ikonik dalam fashion punk :

Tabel 1. Analisis makna item ikonik fashion punk

\begin{tabular}{|c|l|}
\hline \multicolumn{1}{|c|}{ ITEM } & \multicolumn{1}{c|}{ MAKNA } \\
\hline & $\begin{array}{l}\text { Rambut mohawk adalah rambut yang dibuat } \\
\text { berbentuk seperti duri mendongak ke atas. Gaya ini } \\
\text { merupakan adaptasi dari gaya suku indian kuni yang } \\
\text { Rada waktu itu bernama mohican., posisi seperti } \\
\text { menunjuk keatas, rambut dibuat kaku sehingga tidak } \\
\text { mudah layu. Maknanya sebuah perlawanan akan } \\
\text { takdir Tuhan YME, para punk, merupakan gambaran }\end{array}$ \\
\hline
\end{tabular}




\begin{tabular}{|c|c|}
\hline ITEM & MAKNA \\
\hline & $\begin{array}{l}\text { kaum tertindas yang tidak terima dengan posisi } \\
\text { mereka di masyarakat, punk menganggap strata } \\
\text { mereka adalah "takdir" yang dapat dilawan dan } \\
\text { mereka mampu megatasi takdir itu dengan bermusik }\end{array}$ \\
\hline Jens ketat sobek & $\begin{array}{l}\text { Jens ketat yang sobek bermakna sebuah himpitan } \\
\text { dari lingkungan terhadap mereka,yang menghalangi } \\
\text { ruang gerak dan atraksi panggung mereka, oleh } \\
\text { karena itu seringkali muncul robekkan pada lutut } \\
\text { dan paha yaitu sebuah simbol tentang kemerdekaan } \\
\text { gerak dan ide dari para punk }\end{array}$ \\
\hline tatto & $\begin{array}{l}\text { Biasanya bergambar tengkorak, salip, api, dll...tatto } \\
\text { adalah simbol kekuasaan terhadap tubuh/fisik. } \\
\text { Mereka percaya lewat tatto mereka memiliki } \\
\text { kekuasaan penuh terhadap tubuh. Selain itu tatto } \\
\text { juga menyimbolkan cita rasa seni kaum menengah } \\
\text { bawah }\end{array}$ \\
\hline rantai & $\begin{array}{l}\text { Rantai menyimbolkan sebuah kesatuan yang utuh } \\
\text { diantara pa komunitas punk. Faktanya, kesatuan } \\
\text { punk memang terkenal sangat solid, sering kali } \\
\text { mereka terlihat secara bergerombol, berbagi rejeki } \\
\text { dan tempat tidur secara bersama, bahkan diantara } \\
\text { komunitas punk tidak ada diskriminasi berdasarkan } \\
\text { SARA atau secara strata ekonomi }\end{array}$ \\
\hline Piercing / tindik & $\begin{array}{l}\text { Sama seperti tatto, piercing juga menyimbolkan } \\
\text { kekuasaan atas tubuh, perlawanan terhadap } \\
\text { penderitaan/rasa sakit dan mengontrol tubuhnya } \\
\text { sendiri }\end{array}$ \\
\hline Eye shadow & $\begin{array}{l}\text { Eye syadow menyimbolkan cara pandang punk yang } \\
\text { suram terhadap sekitarnya. Bagi punk, masa depan } \\
\text { terlihat sangat suram dan kurang menjanjikan, } \\
\text { seakan-akan mereka siap untuk menjadi kalangan } \\
\text { terbawah sampai akhir hidup mereka }\end{array}$ \\
\hline Sepatu boots & $\begin{array}{l}\text { Sepatu boots biasa dipakai oleh prajurit agar bisa } \\
\text { dipakai di segala medan, baik becek, berbatu, licin } \\
\text { dan medan yang sulit lainya. Oleh karena itu boots } \\
\text { menyimbolkan bahwa para punk akan siap } \\
\text { menghadapi rintangan apapun termasuk hukum dan } \\
\text { kesulitan secara ekonomi. }\end{array}$ \\
\hline
\end{tabular}

Dalam pemahaman teori dusta dari Umberto Eco, semiotika digunakan sebagai cara untuk berbohong, menurut Eco, apa yang bisa mengungkapkan kebohongan juga dapat digunakan sebagai pengungkap kebenaran. Demikian juga dalam fashion punk, asesoris punk banyak digunakan oleh para remaja untuk menutupi identitas dirinya 
sendiri, dengan memakai asesoris punk, mereka membohongi publik dengan menyatakan diri sebagai punker, padahal remaja yang menggunakan fashion punk belum tentu memahami ideologi punk. Bagi para imitator punk (sebutan bagi orang yang suka berdandan ala punk namun tidak menjadi bagian dari komunitas punk), memakai asesoris punk tidak lebih dari lifestyle fashion, atau sebagai adaptasi visual semata. Dengan berdandan seperti punk mereka percaya kalu sedang mengikuti tren atau "necis", yang dilakukan imitator punk adalah sedang memakai tanda/"sign"dari punk kemudian memaknainya secara berbeda, inilah aplikasi dari teori dusta Umberto Eco.

\subsection{IDEOLOGI PUNK}

Inti dari ideologi punk adalah pada motto "D.I.Y (Do It Your Self)", motto ini begitu diyakini dan dihidupi oleh mereka layaknya sebuah ajaran agama. "Do It Your Self" artinya semua dapat dikerjakan sendiri, ideologi ini muncul karena sifat mereka yang anti sosial, mereka tidak mempercayai siapapun diluar komunitas punk, bahkan kecenderungan ideologi mereka selalu berkaitan dengan perlawanan terhadap kekuasaan/politik, anti sosial, minoritas, vandalisme, anti hukum, dan segala hal yang cenderung negatif. Namun dibalik ideologi tersebut sebenarnya ada juga kandungan yang positif, seperti pola hidup mandiri, berkarya (musik) meski dalam keterbatasan, Keberanian dalam mengaktualisasikan diri serta kepercayaan diri yang tinggi. Motto "Do It Yor Self" juga dipahami mereka untuk bertindak seenaknya, akhirnya dalam menyampaikan aspirasi komunitas punk sering melakukan hal-hal yang negatif seperti aksi vandalisme yaitu menaruh atau memuat gambar-gambar yang provokatif (dan/atau jorok), memasukkan pesan-pesan politik, berkali-berkali memuat gambar tanpa informasi sumber atau lisensi, seringkali juga disertai pengrusakan pada fasilitas umum, mengotori jalan dan mengganggu ketertiban. Mengingat sejarahnya yang kelam, ideologi punk sarat dengan hal-hal yang berbau pemberontakan/perlawanan, kebanyakan teraktualisasi menjadi suatu hal yang negatif, oleh karena itu punk sebenarnya dekat dengan kriminalitas, pengangguran, sex bebas, anarki, narkoba, revolusi, dan hal-hal negatif lainya.

\section{KESIMPULAN}

Fashion punk tentunya tidak mengikuti pemahaman dari motto D.I.Y (Do It Your Self), fashion punk atau disebut juga imitator punk hanya memahami punk sebagai trend fashion saja. Mereka tidak mengadaptasi ideologi, namun hanya "punk sebagai tampilan", atau dalam bahasa semiotika stuktural Sausure terdapat istilah "Form" and "Content". Form adalah tampilan sedang content adalah ideologi yang ada di dalamnya. Dalam kata lain fashion punk/imitator punk hanya mengadaptasi "form" bukan "content"nya. 


\section{DAFTAR PUSTAKA}

Barnard, Malcolm, Fashion as Communication, Routledge, 1996; edisi terjemahan Indonesia: Barnard, Malcolm, Fashion sebagai Komunikasi, diterjemahkan oleh Idi Sumandy, Jalasutra, Jogjakarta, 2006

Barthes, Roland, Mythologies, Hill and Wang, New York, 1983

Maria Sari Dian, Identitas Diri Anggota Komunitas Punk Di Bandung, Fakultas Psikologi UNDIP, Semarang, 2010

Martono, Jhon, Punk! Fesyen-Identitas-Subkultur, Halilintar books, Jogjakarta, 2009

Sobur, Alex, Semiotika Komunikasi, Rosda, Bandung, 2003

www.thebrooms28.co.cc/2010/01 
Andharupa, Jurnal Desain Komunikasi Visual \& Multimedia. Vol.01 No.02 Tahun 2015 